\title{
THE CARDIOGRAM OF MITRAL RESTENOSIS
}

\author{
BY \\ H. DEMERDASH* AND J. F. GOODWIN \\ From the Department of Medicine, Postgraduate Medical School of London, Ducane Road, London W.12 \\ Received December 10, 1962
}

The cardiogram of mitral stenosis, with emphasis on right ventricular hypertrophy and $\mathbf{P}$ wave changes before and after mitral valvotomy has been studied previously by Mounsey (1957) and by Rodriguez Torres et al. (1959).

Cardiographic evidence of right ventricular hypertrophy that recurred after valvotomy and increased when restenosis occurred has been presented by Wilcken (1960). The present study elaborates the cardiographic changes before and after mitral valvotomy and at the time of diagnosis of restenosis.

\section{SUBJECTS AND MeTHODS}

The cardiograms before and after mitral valvotomy and at the time of restenosis were studied in 25 patients. Of the 25 patients, 21 had isolated mitral valve disease, predominantly stenosis. The remaining 4 patients in addition to predominant mitral stenosis had either mild aortic valve disease or systemic hypertension.

The clinical diagnosis of restenosis in these patients was based on the following criteria: (a) decrease in effort tolerance following initial improvement after first valvotomy; (b) full-length mitral diastolic murmur; (c) accentuated first heart sound; and (d) absence of significant mitral incompetence.

Right heart catheterization was performed in 15 patients at the time of diagnosis of restenosis (Wilcken, 1960). In all the 15 a high pulmonary "wedge" pressure, slow ' $y$ ' descent in the "wedge" pulse tracing, and the low cardiac output confirmed the diagnosis of initial mitral restenosis.

The clinical diagnosis of restenosis was verified in all the 17 patients who came to a second valvotomy, and cardiograms were available in 15 of them. All cardiograms were taken within the year before, or the year after, the operation respectively.

Cardiographic Criteria Studied. (i) Cardiographic evidence of right ventricular hypertrophy as shown by a dominant $R$ in V4R, V1, aVR, and a dominant S in V5. (ii) Electrical axis (ÂQRS in the frontal plane). (iii) Changes in height, breadth, and shape of $\mathbf{P}$ waves suggesting atrial enlargement, taking the maximum normal height as $2 \mathrm{~mm}$. and the maximum normal breadth as $0 \cdot 1$ second. (iv) Changes in the voltage of RV5 and SV1, assuming this as a cardiographic criterion of the activity of the left ventricle.

Conventional standardization of $1 \mathrm{~cm} .=1 \mathrm{mV}$ was employed in all tracings.

\section{Results}

Cardiographic Evidence of Right Ventricular Hypertrophy (R.V.H.). Of the 25 patients, 13 $(52 \%)$ had cardiographic evidence of right ventricular hypertrophy before valvotomy, and $20(80 \%)$ at the time of restenosis. Cardiographic evidence of right ventricular hypertrophy disappeared in 10 of the 13 patients $(77 \%)$ after the first valvotomy and in 12 of $14(86 \%)$ after the second valvotomy (Fig. 1, 2, and 3).

* Present address: Department of Cardiology, Ein Shams University, Cairo, U.A.R. 


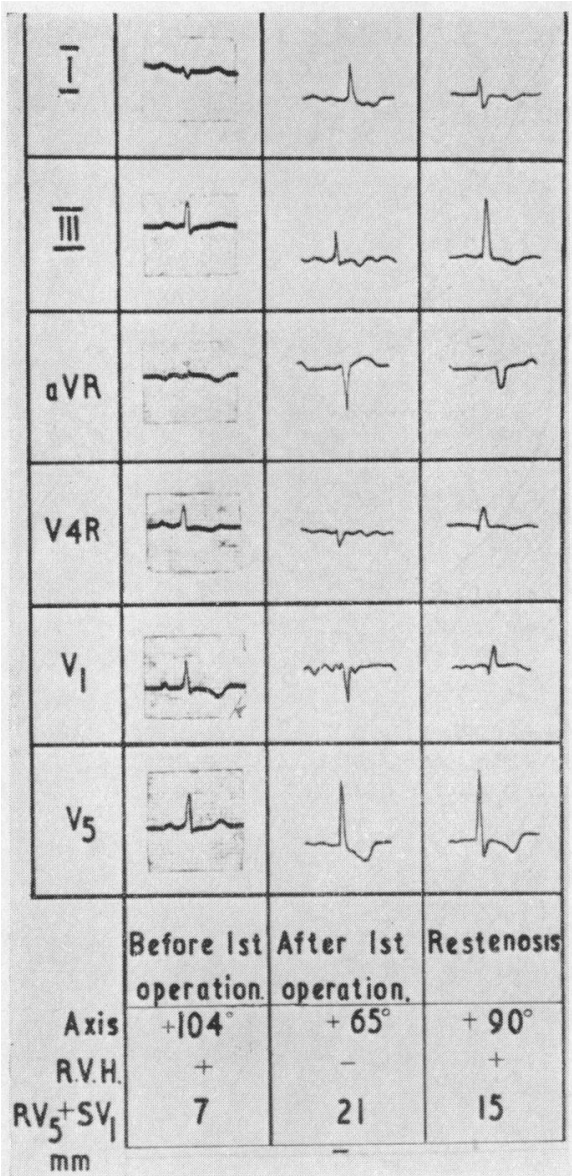

FIG. 1.-Serial cardiograms of a patient illustrating the changes in electrical axis from $+104^{\circ}$ initially to $+65^{\circ}$ after the first valvotomy, and to $+90^{\circ}$ at the time of restenosis. There is also right ventricular hypertrophy (R.V.H.) before the first valvotomy, which resolves and then reappears at the time of restenosis. There is also an increase in voltage of RV5+SV1 after valvotomy and a decrease at the time of restenosis.

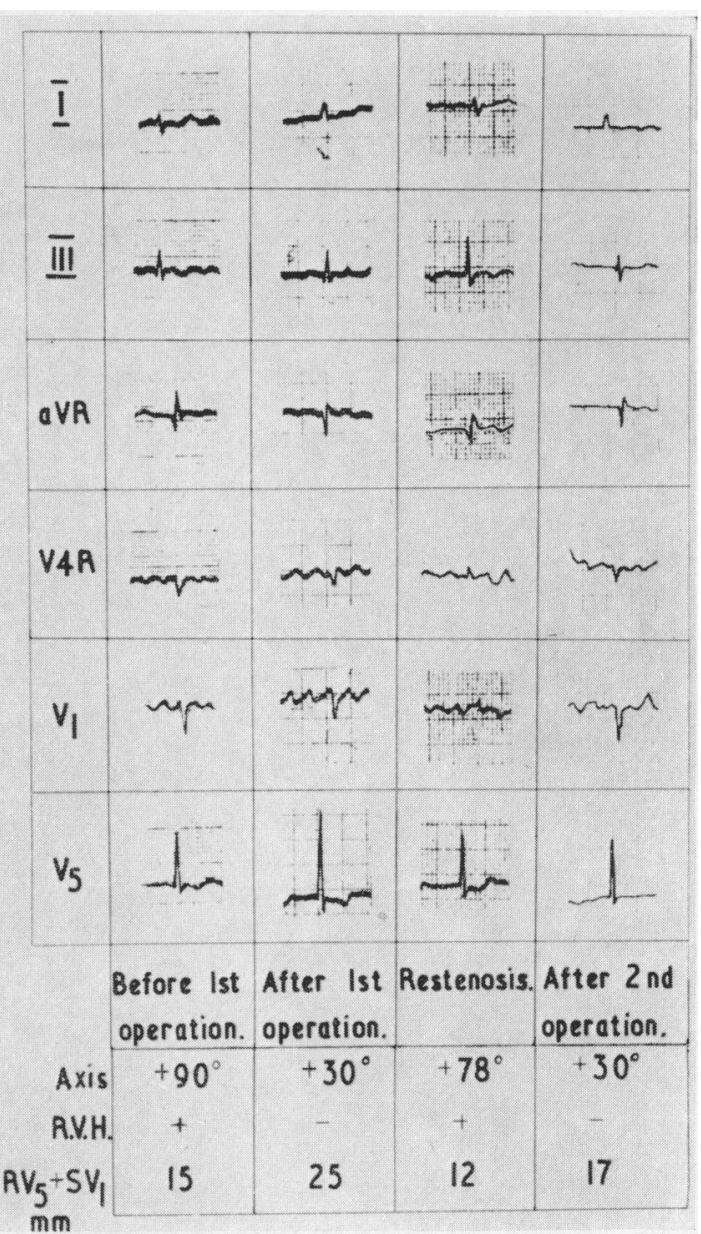

FIG. 2.-Serial cardiograms of a patient illustrating the changes in electrical axis from $+90^{\circ}$ before the first valvotomy to $+30^{\circ}$ after. At the time of restenosis the axis is $+78^{\circ}$ and decreases to $+30^{\circ}$ after the second valvotomy. The cardiogram also shows the disappearance of right ventricular hypertrophy (lead VR) after the first valvotomy, its reappearance at the time of restenosis, and its disappearance after the second valvotomy. There is also increase in the voltage of RV5+SV1 after the first valvotomy, decrease at the time of restenosis, and then a second increase after the second valvotomy.

Electrical Axis. All patients had an electrical axis ranging between $+120^{\circ}$ to $+10^{\circ}$ with a mean value of $+90^{\circ}$. After the first valvotomy all the patients showed a shift toward the left ranging between $+95^{\circ}$ and -10 , with a mean value of $+64^{\circ}$ (Fig. 4).

At the time of restenosis, all the patients studied showed a shift toward the right ranging between $+110^{\circ}$ to $+30^{\circ}$ with a mean of $+87^{\circ}$. After the second valvotomy all the patients studied, except two (Patients 5 and 6) showed a shift towards the left ranging between $+83^{\circ}$ to $-20^{\circ}$ with a mean of $+45^{\circ}$ (Fig. 5). 


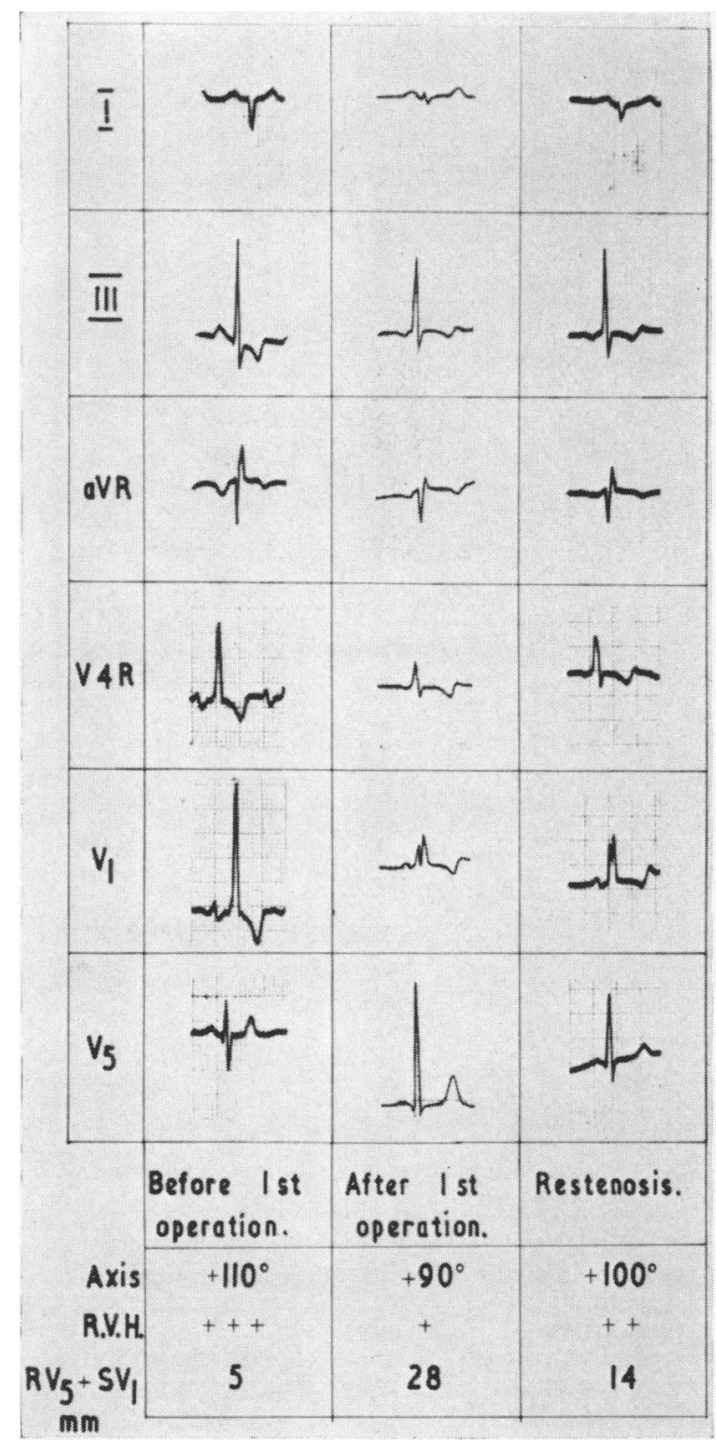

FIG. 3.-Serial cardiograms of a patient with a high total pulmonary vascular resistance (12 units) illustrating little change in the electrical axis from $+110^{\circ}$ before valvotomy to $+90^{\circ}$ after and to $+100^{\circ}$ at the time of restenosis. Right ventricular hypertrophy persists after valvotomy although there is a decrease in the height of the $R$ wave in V4R, V1, and VR, and a decrease in the S wave in V5. There is also increase in the voltage of RV5+SV1 after operation followed by a decrease at the time of restenosis.

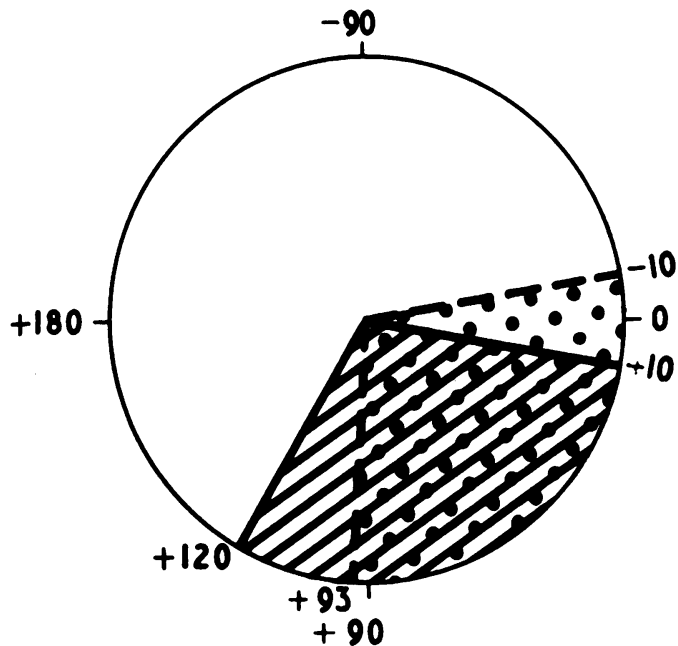

Fig. 4.-Range of electrical axis before and after first mitral valvotomy. (Bars=before operation. Dots $=$ after operation.)

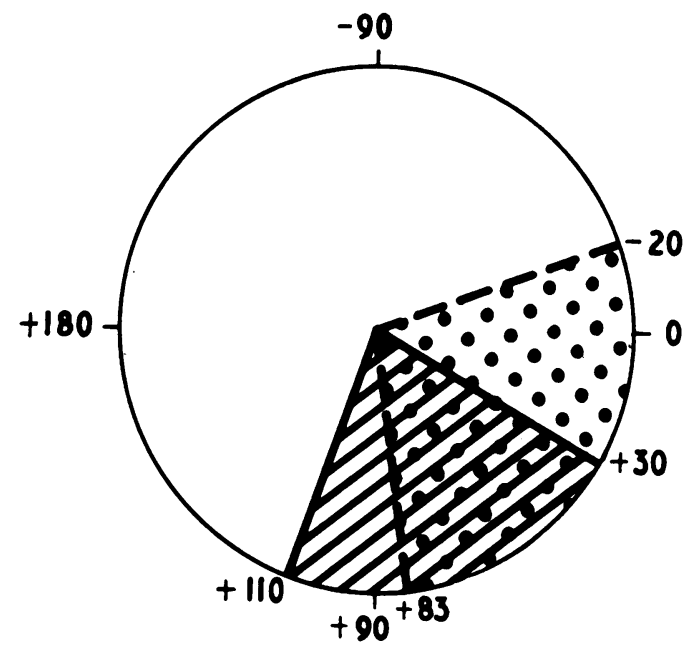

FIG. 5.-Range of electrical axis at the time of restenosis and after second valvotomy. (Bars =before operation. Dots $=$ after operation.) 
$P$ Wave Changes. Before the first valvotomy 17 of the 25 patients studied $(68 \%)$ had sinus rhythm, and $8(32 \%)$ atrial fibrillation. Of the 17 patients with normal sinus rhythm, 13 had abnormally wide bifid $\mathrm{P}$ waves, and the remaining 4 had abnormally tall and wide $\mathrm{P}$ waves indicating combined right and left atrial enlargement. After the first valvotomy 13 patients $(52 \%)$ had normal sinus rhythm, and the remaining $12(48 \%)$ had atrial fibrillation. $\mathrm{P}$ waves that were wide and bifid before operation showed a decrease in breadth, and those that were abnormally tall and wide showed a decrease in breadth and width after operation. At the time of restenosis, 22 patients $(90 \%)$ had atrial fibrillation, and the remaining $3(10 \%)$ were in normal sinus rhythm. One of the 3 patients in normal sinus rhythm had tall peaked $P$ waves and the other 2 had wide bifid $P$ waves.

After the second valvotomy, 14 of the 15 patients had atrial fibrillation.

Voltage of $R V 5+S V 1$. Since the voltage of RV5+SV1 has been assumed to vary with the amount of activity of the left ventricle, the patients have been divided into three groups according to the presence or absence of an associated lesion that might account for increased activity of the left ventricle (Fig. 1, 2, and 3).

Group I. Sixteen patients had tight mitral stenosis with or without mild mitral incompetence, and developed little or no mitral incompetence after valvotomy.

Group II. Five patients had tight mitral stenosis with or without mild mitral incompetence, and developed moderate or severe mitral incompetence after valvotomy.

Group III. Four patients had tight mitral stenosis associated with mild aortic valve disease or systemic hypertension.

In all the patients in Group I, the voltage of RV5+SV1 increased after the first valvotomy, decreased at the time of restenosis, and increased again in all patients except one (Patient 5) after the second valvotomy. All the patients in Group II after the first valvotomy showed a marginally greater rise in the voltage of RV5+SV1 than Group I. At the time of restenosis the voltage of RV5+SV1 decreased in all the patients and subsequently in all of them except one (Patient 6) after the second valvotomy. In all the patients in Group IIl the voltage of RV5+SV1 increased after the first valvotomy, decreased at the time of restenosis, and then increased again after the second valvotomy.

The ranges of the voltage of RV5+SV1 and their average values in all the three groups studied, before and after the first valvotomy, at the time of restenosis, and after the second valvotomy are shown in the Table. The number of patients in each group is too small for statistical analysis, but the changes in average values show a consistent trend.

\section{Discussion}

The present study confirms the work of Wilcken (1960), regarding the disappearance or decrease in the degree of right ventricular hypertrophy after mitral valvotomy, and its reappearance or increase in degree at the time of diagnosis of restenosis.

It is clear from the results that the incidence of right ventricular hypertrophy is higher at the time of restenosis than before the first valvotomy. This suggests that pulmonary hypertension at the time of restenosis may be more severe than before the first valvotomy, and may be a heavy burden on a right ventricle that has residual hypertrophy following the first valvotomy.

The discrepancy between the incidence $(52 \%)$ of cardiographic evidence of right ventricular hypertrophy in the present series and that found by Mounsey (1957) (less than 40\%) and by Rodriguez Torres et al. (1959) $(27 \%)$ is probably due to the fact that lead V4R has been studied, for this has been shown by Camerini, Goodwin, and Zoob (1956) to be the most sensitive lead for the detection of lesser degrees of right ventricular hypertrophy.

The disappearance of cardiographic evidence of right ventricular hypertrophy in the majority of patients after valvotomy is presumably due to the expected fall in pulmonary vascular resistance. 
The three patients who did not show complete disappearance of right ventricular hypertrophy after valvotomy did show diminution in the height of the $R$ wave in leads V4R and V1, indicating regression in the degree of right ventricular hypertrophy (Fig. 3).

Right heart catheterization at the time of diagnosis of restenosis in two of these three patients had shown the presence of raised total pulmonary vascular resistance (12 and 14 units respectively). In the third patient the diagnosis of high pulmonary vascular resistance was based on clinical signs of right ventricular hypertrophy, pulmonary regurgitation, and accentuated pulmonary closure.

In the present study, cardiographic signs of right ventricular hypertrophy disappeared in 77 per cent of patients after the first valvotomy and in 86 per cent of patients after the second valvotomy. This incidence is higher than that of 59 per cent found by Rodriguez Torres et al. (1959), and may be due to the fact that among the present series of 25 patients, there were 4 with associated lesions that may have caused some degree of left ventricular hypertrophy that tended to neutralize the right ventricular signs.

QRS Axis. The shift towards the left of the electrical axis in all patients after the valvotomy may be attributed to the expected regression of right ventricular hypertrophy. At the time of restenosis, the shift of the electrical axis toward the right is presumably due to the increase in right ventricular hypertrophy at this time.

Milnor (1957) has shown by electrocardiographic and vectorcardiographic studies of normal subjects and patients with heart disease that the most important and characteristic electrical change produced by right ventricular hypertrophy is the shift of the QRS axis to the right and anteriorly. After the second valvotomy, the failure of the electrical axis to shift to the left in Patient 5 was probably due to the fact that she had suffered a coronary embolism one year before the second valvotomy. Patient 6 had developed congestive heart failure due to a persistently high pulmonary vascular resistance after the second valvotomy. The diagnosis of high pulmonary vascular resistance in this patient was made on clinical grounds. This could have accounted for the failure of a shift towards the left of the electrical axis in this patient.

Rhythm and $P$ Wave Changes. The present study shows the higher incidence of atrial fibrillation at the time of mitral restenosis $(90 \%)$ as compared with that before the first valvotomy $(32 \%)$. This higher incidence at the time of restenosis may be due to the following factors: first, the life span of patients with tight mitral stenosis is expected to be prolonged after valvotomy, which would favour a higher incidence of atrial fibrillation (de la Chapelle, Graef, and Rottino, 1934). Second, the long-standing stretching and damage to the atrial wall following restenosis may also favour the onset of atrial fibrillation. Third, the progressive nature of the rheumatic disorder that causes restenosis may also cause further atrial damage.

The present study confirms the work of Mounsey (1957) regarding the decrease in the breadth of the $\mathbf{P}$ wave after valvotomy. It also shows the increase in breadth or height of the $\mathbf{P}$ wave in patients with normal sinus rhythm at the time of restenosis. The increase in breadth is due to the increased left atrial pressure due to the mitral obstruction. The increase in height is presumably due to increase in right atrial pressure resulting from an increased pulmonary vascular resistance at the time of restenosis.

Changes in Voltage of RV5+SV1. All patients have shown an increase in the voltage of RV5 + SV1 after the first mitral valvotomy followed by a reduction at the time of restenosis. The increase was noticed not only in RV5, but also in SV1. As shown in the Table, the degree of increase in the voltage was greater in patients who developed moderate or severe mitral incompetence, and less in those who had associated mild aortic valve disease or mild systemic hypertension.

The possible reasons for this general trend after operation are: first, increased activity of the left ventricle after valvotomy due to increased inflow; second, disappearance of the balancing effect of right ventricular hypertrophy in the cardiogram after operation; and third, improvement in myocardial function due to increased coronary flow following an increase in cardiac output.

The difference in the degree of increase in the voltage of RV5+SV1 after valvotomy in the three groups studied is due to the fact that in patients who develop moderate or severe mitral incompetence 
TABLE

Range and Average Value of RV5+SV1 in Three Groups Before and After Two Valvotomies, and at TIME OF RESTENOSIS

\begin{tabular}{|c|c|c|c|c|c|c|c|c|}
\hline & $\begin{array}{c}\text { Range of } \\
\text { RV5+SV1 } \\
\text { before 1st } \\
\text { valvotomy } \\
(\mathrm{mm} .)\end{array}$ & $\begin{array}{c}\text { Average } \\
(\mathrm{mm} .)\end{array}$ & $\begin{array}{c}\text { Range of RV5 } \\
\text { +SV1 after } \\
\text { 1st valvotomy } \\
\text { (mm.) }\end{array}$ & $\begin{array}{c}\text { Average } \\
(\mathrm{mm} .)\end{array}$ & $\begin{array}{l}\text { Range of RV5 } \\
+\mathrm{SV} 1 \text { at time } \\
\text { of restenosis } \\
\quad(\mathrm{mm} .)\end{array}$ & $\begin{array}{c}\text { Average } \\
(\mathrm{mm} .)\end{array}$ & $\begin{array}{c}\text { Range of RV5 } \\
\text { +SV1 after } \\
\text { 2nd operation } \\
\text { (mm.) }\end{array}$ & $\begin{array}{c}\text { Average } \\
(\mathrm{mm} .)\end{array}$ \\
\hline $\begin{array}{l}\text { Group I } \\
\text { Group II } \\
\text { Group III }\end{array}$ & $\begin{array}{r}4-26 \\
7-14 \\
21-32\end{array}$ & $\begin{array}{l}14 \\
10 \\
27\end{array}$ & $\begin{array}{l}17-29 \\
22-30 \\
23-39\end{array}$ & $\begin{array}{l}22 \\
26 \\
33\end{array}$ & $\begin{array}{r}10-20 \\
7-18 \\
10-23\end{array}$ & $\begin{array}{l}15 \\
14 \\
19\end{array}$ & $\begin{array}{l}15-30 \\
22-39 \\
28-49\end{array}$ & $\begin{array}{l}20 \\
32 \\
38\end{array}$ \\
\hline
\end{tabular}

the left ventricle may be expected to do more work than in those who have little or no mitral incompetence. The small increase in voltage of RV5+SV1 in patients with aortic valve disease or systemic hypertension after operation is due to the fact that the voltage is initially increased in these patients due to the presence of some degree of left ventricular hypertrophy.

The decrease in voltage of RV5+SV1 at the time of restenosis is probably due to increasing right ventricular hypertrophy and diminishing left ventricular activity.

After the second valvotomy, the failure of RV5+SV1 to increase in two patients was probably due to previous coronary embolism with resulting localized myocardial fibrosis in Patient 5, and to congestive heart failure resulting from a persistently high pulmonary vascular resistance in Patient 6 .

\section{SUMMARY}

A study of serial cardiograms of 25 patients who came to mitral valvotomy and subsequently developed restenosis has shown a shift towards the left of the electrical axis after mitral valvotomy followed by a shift to the right at the time of restenosis. Failure of the electrical axis to shift towards the left after the second valvotomy occurred in a patient who had localized myocardial fibrosis due to previous coronary embolism and in those who had a persistently raised pulmonary vascular resistance and cardiographic evidence of right ventricular hypertrophy after valvotomy.

Right ventricular hypertrophy disappeared or decreased after successful valvotomy, but reappeared or increased at the time of restenosis.

The sum of the voltage of RV5+SV1 increased after valvotomy and decreased at the time of restenosis, reflecting increased, and then diminished, left ventricular activity. The voltage of RV5 + SV1 failed to increase after the second valvotomy in patients who had suffered a coronary embolism previously, or had congestive heart failure due to persistently high pulmonary vascular resistance with right ventricular hypertrophy.

The incidence of atrial fibrillation was higher at the time of restenosis $(90 \%)$ than before the first valvotomy $(32 \%)$.

Patients who remained in normal sinus rhythm after operation showed a reduction in breadth or height of the $\mathbf{P}$ wave after operation, and an increase again at the time of restenosis.

The results show the value of studying in serial cardiograms the cardiac axis, evidence of right ventricular hypertrophy, voltage of RV5+SV1, rhythm, and P wave changes in the assessment of patients with suspected mitral restenosis.

\section{REFERENCES}

Camerini, F., Goodwin, J. F., and Zoob, M. (1956). Lead V4R in right ventricular hypertrophy. Brit. Heart J.,

de la Chapelle, C. E., Graef, I., and Rottino, A. (1934). Studies in rheumatic heart disease. Amer. Heart J., 10, 62. 
Milnor, W. R. (1957). Electrocardiogram and vectorcardiogram in right ventricular hypertrophy and right bundlebranch block. Circulation, 16, 348.

Mounsey, P. (1957). Determination of success after mitral valvotomy: Role of circulatory obstruction of the myocardium and of other factors. Brit. med. J., 2, 311.

Rodriguez Torres, R. V. R., Mackinnon, J., Wade, E. G., and Vickers, C. F. H. (1959). Persistence of right ventricular hypertrophy following mitral valvotomy. Brit. Heart J., 21, 381.

Wilcken, D. E. L. (1960). Mitral valvotomy and restenosis. Brit. med. J., 1, 681. 